\title{
Professional Volleyball Development in Taiwan's Sports Industry
}

\author{
Lin-Huan Hu${ }^{1}$, Chih-Fu Cheng ${ }^{2}$, and Jei-Zheng $\mathrm{Wu}^{3 *}$ \\ ${ }^{1}$ Department of Athletics, National Taiwan University \\ 1, Roosevelt Road, Section 4 \\ Taipei, 10617, Taiwan \\ lhhu@ntu.edu.tw \\ ${ }^{2}$ Department of Physical Education, National Taiwan Normal University \\ 162, He-ping East Road, Section 1 \\ Taipei, 10610, Taiwan \\ jeff@ntnu.edu.tw \\ ${ }^{3}$ Department of Business Administration, Soochow University \\ 56 Kueiyang Street, Section 1 \\ Taipei, 10048, Taiwan \\ *jzwu@scu.edu.tw
}

Received 31 August 2017

Accepted 10 May 2018

\begin{abstract}
This study determined the aspects required to professionalize volleyball, by analyzing the literature and interviewing 11 experts and scholars. The criteria of assessments were set, and the strategies of promotion were delivered. We discovered the points of view on the professionalization of volleyball in Taiwan based on six dimensions and 30 criteria. The DEMATEL results show that Quality of Team Management and Stupendousness of the Game are the driving factors with a dominating influence on the performance of other dimensions.
\end{abstract}

Keywords: Professional Sports; Volleyball; Fuzzy Delphi Method; Decision-Making Trial and Evaluation Laboratory (DEMATEL); Analytic Network Process (ANP) 


\section{Introduction}

The sports industry is a target of development for the Taiwan government. The sports industry in North America is profitable and the market sales is expected to reach US\$73.5 billion by 2019. ${ }^{1}$ According to information from the Fédération International de Volleyball, volleyball has become one of the top five international sports. Volleyball's audience and worldwide participation have grown steadily-it is enjoyed by all ages and genders. Each year, the World Men's Volleyball League, Women's Volleyball Grand Prix, and quadrennial World Cup attract many viewers. Recently, these international sports competitions have become a major platform for sports marketing. National and international women's volleyball competitions have already set monetary awards for winning teams. The sum of the prizes in volleyball sponsored by the world's leading enterprises was just as substantial as that of other main sports. Professional leagues quickly formed for America's women's basketball and soccer after success in international competitions. A grand prix has been initiated even for track, which valued sports spirit the most. Judging by the aforementioned series of events, volleyball will develop toward professionalization. Many countries that have already moved in that direction have had tremendous success, for example, Italy, Turkey, and Japan.

According to PricewaterhouseCoopers (PwC) Sports Outlook, ${ }^{1}$ the 2014 sports market in North America rose to US\$60.5 billion. After the development of Taiwan's major domestic sporting events in professional baseball in 1990 and professional basketball in 1994, an enterprise league for volleyball was created in 2004 that raised the competitive and market level of the sport. As a result, the basis of enterprise volleyball will lead to the establishment of professional volleyball in Taiwan, which is one of the government's goals.

Studies on professional sports in Taiwan have mostly focused on team marketing strategy or brand recognition; ${ }^{2,3,4}$ however, they failed to provide insights and key factors regarding progression and promotion toward professionalization, which require substantial multiple criteria decision analysis based on computational intelligence and data science. Notably, the sports industry has been applying quantitative techniques to information intelligence to strengthen game competition and market development. Yet, less documented is how to model and analyze complex interrelated multiple criteria and enhance decision quality and management effectiveness for sports industry development and professionalization. Because of the richness of the collected data, analysis would be more efficient and the decision-making process more accurate with the help of computational intelligence tools, to provide diverse views on the development strategy for professional volleyball in Taiwan and suggestions on policy and practice.

Therefore, this study aims to provide an assessment standard and establish the importance of professional development through the collection of literature and analysis of the sports industry, government policy, academia, and interviews. The quantitative decisionmaking trial and evaluation laboratory (DEMATEL) and analytic network process (ANP) were used to analyze data from an expert questionnaire, and a complete model of key factors for professionalizing volleyball was proposed to provide a reference and basis for the feasibility of professional volleyball. This study also demonstrates how modeling and decision analysis can be extended from decision-making to the field of professional sports.

Because the traditional Delphi method of data collection requires more time and research assistants than is often feasible, the fuzzy Delphi method has been widely adopted in studies and business strategy development. 5,6,7,8 The ANP and DEMATEL are recognized as robust approaches and therefore are applied in a wide area of research, such as making strategic decisions..$^{9,10,11,12}$ ANP helps decision-makers to formulate and analyze multiple criteria based on a network structure. ${ }^{12}$

To the best our knowledge, this study is the first attempt to investigate complex interrelations among key factors of developing professional volleyball in the sports industry by using the novel integration of fuzzy Delphi and the DEMATEL-based analytic network process (DANP). Identification of such key factors is achieved by two means: first, to investigate which criteria have higher weights to promote the professional volleyball; and second, to highlight any interrelationships among the key factors that would suggest the drivers initiate the promotion and enhancement. The findings in this paper are expected to add values to knowledge and drawing implications for government and managers involved in the sports industry, as a reference model for their organizations to develop operating strategy continually.

The remainder of this paper is organized as follows. Section 2 presents the methods, namely fuzzy Delphi, DEMATEL, and ANP. Sections 3 to 5 present the results and discussions of fuzzy Delphi, DEMATEL, and ANP, respectively. Section 6 concludes with discussions on proposed directions of future research. 
Table 1. Profile of the Interviewees $(\mathrm{n}=11)$

\begin{tabular}{|c|c|c|c|}
\hline No. & Category & Position & Experiences \\
\hline 1 & Government & General Secretary, Chinese Taipei Volleyball Association & $\begin{array}{l}\text { - Chairman, Top Volleyball League } \\
\text { - Referees Committee, Asian Volleyball Confederation }\end{array}$ \\
\hline 2 & Government & $\begin{array}{l}\text { Supervisor, Competitive Athletics Division, Sports } \\
\text { Administration, Ministry of Education }\end{array}$ & - Coach, Chinese Taipei Men's Volleyball Team \\
\hline 3 & Academia & $\begin{array}{l}\text { Professor and Chairperson, Physical Education Office, } \\
\text { National Taiwan University }\end{array}$ & $\begin{array}{l}\text { - Secretary General \& Executive Director, } \\
\text { Taiwan Society for Sport Management }\end{array}$ \\
\hline 4 & Academia & $\begin{array}{l}\text { Assistant Professor, Physical Education Office, } \\
\text { National Taiwan University }\end{array}$ & $\begin{array}{l}\text { - Outstanding Young Scholar Research Project (Sports } \\
\text { Marketing), Ministry of Science and Technology }\end{array}$ \\
\hline 5 & Academia & $\begin{array}{l}\text { Associate Professor and Coach of the Men's Volleyball } \\
\text { Team, National Taiwan University of Sport }\end{array}$ & - Player, Chinese Taipei Men's Volleyball Team \\
\hline 6 & Academia & $\begin{array}{l}\text { Associate Professor and Coach of the Men's and Women's } \\
\text { Volleyball Team, National Taiwan Normal University }\end{array}$ & $\begin{array}{l}\text { - Player, Chinese Taipei Men's Volleyball Team } \\
\text { - Coach, Chinese Taipei Women's Volleyball Team }\end{array}$ \\
\hline 7 & Industry & $\begin{array}{l}\text { Professor and Chairperson, Physical Education Office, } \\
\text { Chung Yuan Christian University }\end{array}$ & - Coach, Chinese Taipei Men's Volleyball Team \\
\hline 8 & Industry & $\begin{array}{l}\text { Assistant Professor and Coach of the Men's Volleyball } \\
\text { Team, National Changhua University of Education }\end{array}$ & - Player, Chinese Taipei Women's Volleyball Team \\
\hline 9 & Industry & $\begin{array}{l}\text { Assistant Professor and Coach of the Men's Volleyball } \\
\text { Team, National Taipei University of Education }\end{array}$ & $\begin{array}{l}\text { - Player, Chinese Taipei Men's Volleyball Team } \\
\text { - TV Volleyball Commentator }\end{array}$ \\
\hline 10 & Industry & $\begin{array}{l}\text { Coach of the Men's Volleyball Team, New Taipei } \\
\text { Municipal Jui-Fang Industrial High School }\end{array}$ & $\begin{array}{l}\text { - Player, Chinese Taipei Men's Volleyball Team } \\
\text { - Coach, Mizuno Men's Volleyball Team, } \\
\text { Top Volleyball League }\end{array}$ \\
\hline 11 & Industry & $\begin{array}{l}\text { Assistant Coach of the Men's Volleyball Team, } \\
\text { Top Volleyball League }\end{array}$ & $\begin{array}{l}\text { - Information Division, AVC Club Volleyball Championship } \\
\text { - Information Division, Top Volleyball League }\end{array}$ \\
\hline
\end{tabular}

\section{Methods}

This study applied the group decision model to collect the opinions of the survey committee, which consisted of 11 experts from the government, the industrial circle, and academia. The sample size is appropriate, ${ }^{13}$ as Delbecq ${ }^{14}$ suggested that the sampling error is lowest when the number of experts falls between 10 and 30 . This study involved interviewing eleven senior experts with an average experience of more than 15 years (Table 1) in Taiwan's volleyball academia, industry and government subdivision to acquire in-depth knowledge regarding their perception of professional volleyball development. During the survey process, the senior experts possess a high degree of conversational flexibility to express their personal perspectives and relevant experiences. The fuzzy Delphi method helps to converge the experts' responses more efficiently with less ambiguity and uncertainty. ${ }^{15,16,17}$

The ANP is a generalization of the analytic hierarchy process (AHP) that can consider interrelations among factors. ${ }^{18}$ Existing studies ${ }^{19,20}$ have shown that the results of the ANP were more meaningful than those of the AHP. More applications and details of DEMATEL and the DANP are provided in previous studies..$^{21,22,23}$ In this study, we applied the standard DANP steps. ${ }^{22,23,24}$
- Step 1: Calculate the direct-influence matrix according to the scores and test their reliability.

- $\quad$ Step 2: Normalize the direct-influence matrix.

- Step 3: Attain a total-influence matrix.

- Step 4: Analyze the DEMATEL results. Identify thresholds to highlight the key influence in the total-influence matrix, and calculate the prominences and relationships to devise a relationship diagram for identifying the criteria in the core, driving, independent, and influenced factor zones.

- Step 5: Find the normalized total-influence matrix.

- $\quad$ Step 6: Find the normalized matrix by using the dimensions and criteria.

- $\quad$ Step 7: Create an unweighted supermatrix.

- Step 8: Find the influential weights of the DANP.

- $\quad$ Step 9: Obtain the global weights of the criteria by using the limit supermatrix of the DANP.

A novel integration of fuzzy Delphi and DANP is proposed whereas the former identifies the key criteria followed by the later analysis on criteria interrelations and importance. Both methods have shown their applicability to multiple criteria decision-making problems. Yet, both of them have drawn little attention in the field of the sports industry. 
Table 2. Average input direct-influence matrix of dimensions

\begin{tabular}{ccccccc}
\hline Dimension & A & B & C & D & E & F \\
\hline A. Quality of Team Management & 1.390 & 1.552 & 1.744 & 1.699 & 1.769 & 1.779 \\
B. Development of Volleyball at Basic Level & 1.527 & 1.446 & 1.783 & 1.715 & 1.785 & 1.775 \\
C. Stimulation of Sports Industry & 1.659 & 1.732 & 1.781 & 1.904 & 1.952 & 1.939 \\
D. Application of Marketing Strategy & 1.703 & 1.744 & 2.003 & 1.760 & 1.983 & 1.985 \\
E. Stupendousness of the Game & 1.791 & 1.848 & 2.073 & 2.015 & 1.909 & 2.088 \\
F. Competitive System of Professional Volleyball & 1.737 & 1.781 & 1.994 & 1.938 & 2.019 & 1.839 \\
\hline
\end{tabular}

Table 3. Strengths of influence for dimensions

\begin{tabular}{|c|c|c|c|c|}
\hline Dimension & $\begin{array}{l}\text { Sum of Columns } \\
\text { (D) }\end{array}$ & $\begin{array}{c}\text { Sum of Rows } \\
\text { (R) }\end{array}$ & $\begin{array}{c}\text { Prominence } \\
(\mathrm{D}+\mathrm{R})\end{array}$ & $\begin{array}{r}\text { Relation } \\
(\mathrm{D}-\mathrm{R}) \\
\end{array}$ \\
\hline A. Quality of Team Management & 9.933 & 9.807 & 19.740 & 0.126 \\
\hline B. Development of Volleyball at Basic Level & 10.031 & 10.103 & 20.134 & -0.072 \\
\hline C. Stimulation of Sports Industry & 10.968 & 11.380 & 22.347 & -0.412 \\
\hline D. Application of Marketing Strategy & 11.178 & 11.030 & 22.208 & 0.148 \\
\hline E. Stupendousness of the Game & 11.724 & 11.416 & 23.140 & 0.307 \\
\hline F. Competitive System of Professional Volleyball & 11.309 & 11.406 & 22.714 & -0.097 \\
\hline
\end{tabular}

\section{Fuzzy Delphi Results}

This study used relevant literature as a reference to formulate initial strategic guidelines for developing and promoting professional volleyball in Taiwan. Each literary work was evaluated according to the direction and content applicable to Taiwan's development of professional volleyball, and the evaluation consisted of five dimensions and 24 criteria. After the first phase of screening the fuzzy Delphi method questionnaire and after the 24 criteria achieved convergence, experts suggested adding one extra dimension and 20 extra criteria, as well as modifying 13 of the previous criteria, forming a total of six dimensions and 44 criteria. The criterion categories had to obtain $80 \%$ of the experts' approval (only one or two people could disapprove), and the threshold value had to be $\geq 7.60$. Of the 44 criteria, two were suggested to be omitted by more than three experts, nine did not reach the threshold value, and three did not meet convergence. After discussing the results, the experts and scholars deleted the 14 aforementioned criteria. The omitted criteria ratio was $32 \%$.

This study found that Taiwan's strategic development toward professionalization of volleyball could be categorized into six dimensions: Quality of Team Management, Development of Volleyball at Basic Level, Stimulation of Sports Industry, Application of
Marketing Strategy, Stupendousness of the Game, and Competitive System of Professional Volleyball. Some results of this study reflect opinions contributed by other scholars. $^{25,26}$ A comprehensive review of scholarly opinions showed that compared with other dimensions, Application of Marketing Strategy, Stupendousness of the Game, and the Competitive System of Professional Volleyball were discussed more frequently. Today, volleyball is recognized as a product sponsored and adopted by large enterprises, and because there has been no clear relationship to the public, a marketing strategy was created. Although broadcasting has already integrated National Taiwan Sport University's sports information and broadcasting major for live streaming, limitations in personnel, equipment, and the environment have restricted the viewing quality, thus reducing the stupendousness of the game. Partnerships between businesses, leagues, and consumers should be strengthened to increase the effectiveness of the sponsorship, and enterprise volleyball should be developed with the support of consumers to create a winwin situation.

\section{DEMATEL Results}

This study used the DEMATEL method to analyze the influences among all dimensions to form a relationship matrix, shown in Table 2. Table 3 indicates the strengths 
of influence for the dimensions. The value (D) shows the column sum and represents the influence of the respective dimension. The value $(\mathrm{R})$ shows the row sum and represents the affected value of the respective dimension. The value $(D+R)$ shows the centrality. The higher the value of $(D+R)$, the higher the level of influence on the relationship between the two dimensions is. The value $(\mathrm{D}-\mathrm{R})$ is the cause value and represents the affected influence level; a positive value indicates that the dimension is more likely to influence other dimensions, whereas a negative value indicates that the dimension is more likely to be affected by other values.

Figure 1 shows a causal diagram of dimensions for Taiwan's professional volleyball development. The horizontal axis represents the centrality of the dimensions, the vertical axis represents the level of causation, and the arrows indicate the influence relationships between dimensions, either direct or indirect. The dimension Stupendousness of the Game is located in the first quadrant and valued the highest with respect to centrality and level of causation, signifying it as the driving factor; it also falls toward the cause category, which means that it influences other dimensions. Thus, this dimension should be the most prioritized target for improvement. Application of Marketing Strategy also falls in the first quadrant and cause category, thus marking it as a prioritized target for improvement. Quality of Team Management has the lowest centrality, but because the level of causation is positive, it should be the next priority after the two dimensions previously mentioned. The dimensions Competitive System of Professional Volleyball and Stimulation of Sports Industry have high centrality, but the level of causation is negative and falls in the fourth quadrant. This indicates that the two dimensions fall within the result category and are easily influenced by other categories. Thus, the factors in the first quadrant should have priority over these two dimensions. Development of Volleyball at Basic Level falls in the third quadrant. Because the centrality and causation level are lower than average, the dimension is more independent and has a lower causation level. Thus, prioritizing this dimension for improvement is not recommended.

This study discovered that Taiwan's development of professional volleyball can be categorized into six dimensions. The weighted values of resources invested in the six dimensions are shown in Figure 1. The dimensions located in the first quadrant, Stupendousness of the Game and Application of Marketing Strategy, have the greatest effect. The success of these two dimensions greatly influences the performance of the other dimensions. Thus, investing the greatest amount of resources in these two dimensions is recommended. Located in the second quadrant with less priority, Quality of Team Management has a driving characteristic that can partially influence the development of other dimensions. Thus, investing up to $80 \%$ of the total weighted value of management resources in the two aforementioned quadrants is recommended. The dimensions located in the third quadrant, Development of

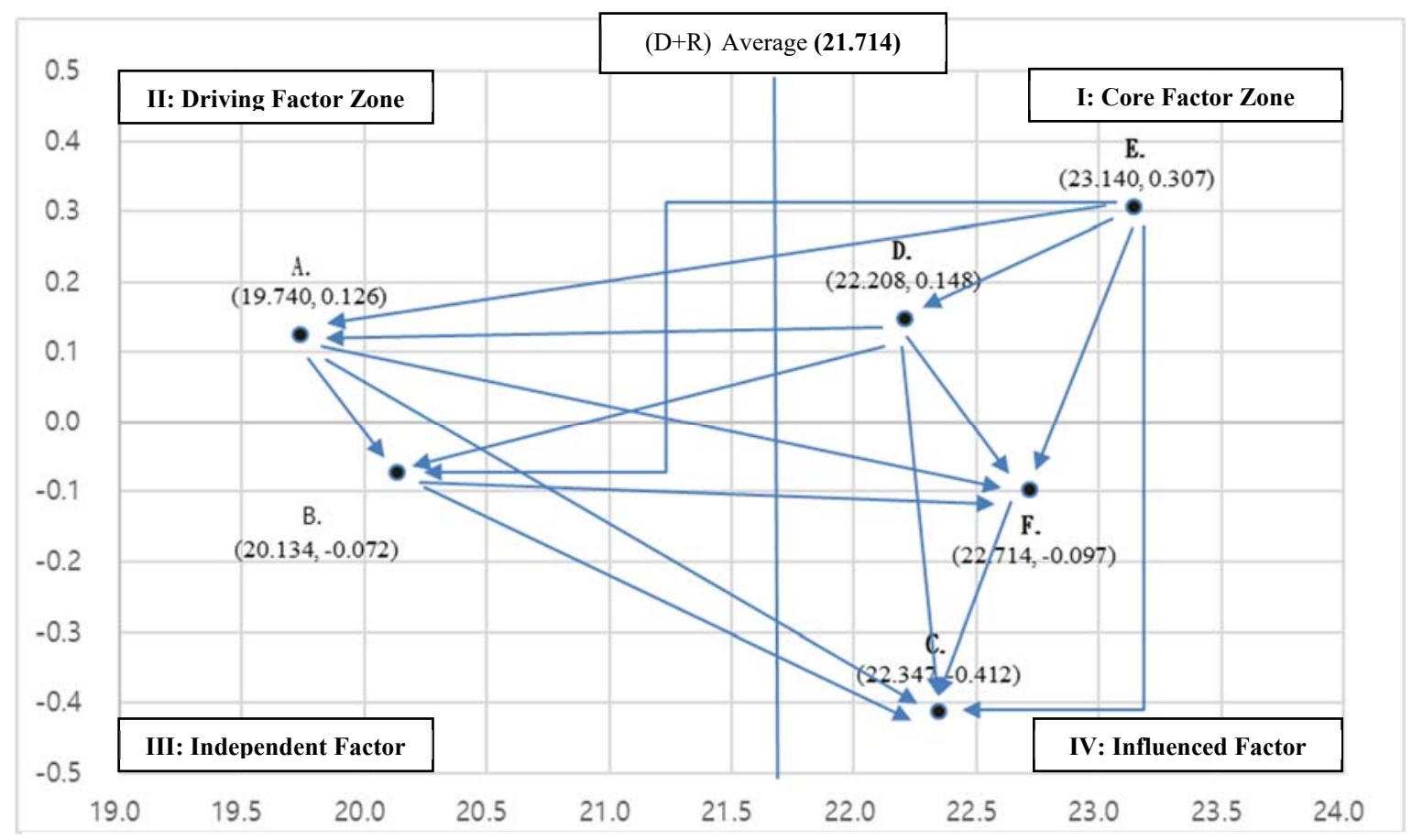

Figure 1. Diagram of Taiwan's professional volleyball development dimensions. 
Volleyball at Basic Level and Stimulation of Sports Industry, are categorized as independent factors because they have less frequent interactions with other dimensions. Thus, they should be managed individually and considered in the tertiary level of priority. Lastly, the dimensions located in the fourth quadrant, Competitive System of Professional Volleyball and Stimulation of Sports industry, are easily affected by other dimensions. Actually, other dimensions with driving and influence factors develop these dimensions. Thus, placing these two dimensions at the bottom of the priority list is recommended. The results indicate that representatives from enterprises, the government, and academia consistently considered the development of Stupendousness of the Game, Application of Marketing Strategy, and Quality of Team Management to be the most effective in driving the development of professional volleyball in Taiwan.

Today, enterprises do not provide players with steady sponsorship, with sponsors changing almost annually. Additionally, sponsoring enterprises fail to guarantee future work opportunities for athletes, which causes them to withdraw and pursue other occupations. This has been a significant loss to Taiwan. Several criteria must be met, such as drawing in large enterprises other than Taiwan Power Company to sponsor or form volleyball teams, stabilizing the stance of each supporting enterprise, and guaranteeing working opportunities for athletes to increase confidence in enterprise leagues. These criteria will enable athletes to perform to their fullest in games and practice, thus increasing the stupendousness of the game. Therefore, through government policies that grant benefits to companies that establish an enterprise team, guarantee work opportunities for athletes, and provide tax relief, enterprises would be more likely to invest in the sports industry and raise the standard of professional volleyball.

The criteria that fall into the first quadrant are A1. Establish a well-furnished system for pay and benefits; B3. Establish sponsorship platform for basic level teams; E3. Increase the maturity of the league and attract foreign skilled athletes; F1. Establish a complete draft system; and F2. Establish complete association regulation and competition rules. Because these indicators have a higher influence on others, these indicators should have priority for improvement. The indicators located in the second quadrant are as follows: A2. Establish a well-furnished administrative method and reward system for players and coaches; A3. Establish a sound insurance system for players and coaches; A4. Establish a coach training system; B1. Strengthen youth, college, and amateur skill levels; B2. Strengthen coaching expertise and tactical ability; B4. Create events for professional teams to teach in the countryside; C1. Seize opportunities to host prestigious international events; and $\mathrm{C} 2$. Increase interaction between international and professional volleyball leagues. These criteria can also influence other criteria and should have priority after the criteria in the first quadrant. The indicators located in the third quadrant are as follows: C5. Increase the sales of mascots and souvenirs in exclusive competitions; D6. Establish complete statistics of offense and defense, and post them on official websites; F3. Establish a system of wage arbitration; and F4. Establish a trade system between teams. Because these criteria have a weak relationship with other criteria, controlling these criteria individually is recommended. Lastly, criteria located in the fourth quadrant are as follows: C3. Establish a ticketing system and develop patterns for audience ticket purchase; C4. Establish a platform for team sponsorship; D1. Establish territorialism and regulate local fans; D2. Each team develops a system to develop unique characteristics of fans; D3. Create brand recognition for each team; D4. Emphasize the upkeep of star players' public image and conduct; D5. Establish a link between official website and social media, to strengthen marketing; D7. Integrate cross-industry marketing to develop fans; D8. Develop a service platform to assist fans; D9. Strategize marketing and media planning; E1. Improve the standard of competitions and athletes; E2. Facilitate improvement of professional media coverage and quality; and F5. Establish a system for all-star games. The 13 criteria in the fourth quadrant should not be developed directly, but enhanced through the growth of other criteria.

\section{DANP Results}

This study calculated the weight between each dimension and criterion using the DANP. Of the six dimensions, E. Stupendousness of the Game was weighted the highest with the value of 0.180 , followed by F. Competitive System of Professional Volleyball with 0.174, D. Application of Marketing Strategy with 0.172, C. Stimulation of Sports Industry with 0.168, B. Development of Volleyball at Basic Level with 0.154, and A. Quality of Team Management, with 0.152 .

In the analysis of criterion weights, as shown in Table 4, the 10 strategic criteria that were weighted the most in descending order are as follows: E1. Improve the standard of competitions and athletes, with a value of 0.067 ; E3. Increase the maturity of the league and attract foreign skilled athletes, with 0.060 ; E2. Facilitate improvement of professional media coverage and quality, with 0.053 ; B3. Establish a sponsorship platform for basic level teams, with 0.043; A1. Establish a wellfurnished system for pay and benefits, with 0.042; B1. Strengthen youth, college, and amateur skill levels, with 
0.040; A2. Establish a well-furnished administrative method and reward system for players and coaches, with 0.038 ; B2. Strengthen coaching expertise and tactical ability, with 0.037 ; F2. Establish complete association regulations and competition rules, with 0.037 ; and F1. Establish a complete draft system, with 0.037 .

The goal of this study was to determine the weights of contributing factors that have a positive impact on the development of professional volleyball and provide suggestions on how to manage resources accordingly, efficiently, and properly. Through the literature review, scholarly surveys, and the analysis of six dimensions and 30 criteria by using the fuzzy Delphi method, experts formed a consensus that Stupendousness of the Game, Application of Marketing Strategy, and Quality of Team Management are the top three primary dimensions that could drive the professionalization of volleyball in Taiwan. The recommended steps are detailed as follows.

\subsection{Stupendousness of the Game}

On the enterprise league level, in addition to raising the skill level of players, coaches, and teams, the balance between teams is an important factor influencing the stupendousness of the game. The addition of foreign athletes to Taiwan's professional sports teams is a policy that has resulted in great success during the past 11 years. Foreign players elicited excitement, brought attention to volleyball teams "Taichung LianZhuang" and "ChungKun," raised the stupendousness of the game, and balanced the skill level of the league. Therefore, the introduction of foreign players into the enterprise leagues to increase the excitement between the offense and defense as well as the stupendousness of the game overall should continue.

\subsection{Application of Marketing Strategy}

It is crucial to establish territorialism to enhance local identity among fans and then establish a home and away system based on the location of the enterprise team. This step increases topicality, functions harmoniously with souvenir promotion, and establishes behavior patterns for ticket purchase by fans. Strategic media advertising plans can increase the viewing potential of enterprise volleyball and establish a bridge between an official website and social media to enhance the popularity and informational exposure of the enterprise volleyball league. Furthermore, offering complete statistical analyses for fans and the community increases interaction between the fans and enterprise volleyball teams by establishing recognition of star players and each team's brand. A sense of belonging and coherence among fans can be developed by planning events and competitive matches. Moreover, athletes can connect with volleyball classes at the college level to promote volleyball within the community. These plans increase opportunities for athletes to attract fans, particularly young fans, and initiate strategic marketing.

\subsection{Quality of Team Management}

It is also crucial to begin with systematic reformation, that is, to establish a well-furnished administrative method and reward system for players and coaches, a management method, and a safety net for occupational opportunities. A well-constructed system attracts will increase the number of talented players. Increasing the salary and wages for coaches and players also attracts athletes to join enterprise volleyball and increases the stupendousness of the game. Hiring team managers is another key action.

Today, the enterprise volleyball league is under the Chinese Taipei Volleyball Association. There are neither members nor an organization that operates independently. According to the DEMATEL results, Stupendousness of the Game and Quality of Team Management are the core driving factors. These two dimensions can greatly affect the performance of other dimensions. Therefore, successful planning and promotion of an enterprise volleyball competition system by team managers will support the progression of enterprise volleyball into semiprofessionalization and, ultimately, professionalization.

\section{Concluding Remarks}

Computational intelligence is suitable for multidisciplinary research projects and useful within the domain of sports. This study aims to investigate the key factors of promoting the development of professional volleyball in the Taiwan sports industry. By collecting and analyzing relevant literature and by interviewing experts and scholars, important aspects for the professionalization of volleyball were determined. Using a diagram of Taiwan's professional volleyball 
Table 4. Criteria Weights

\begin{tabular}{|c|c|c|}
\hline Dimension & Criterion & Weight \\
\hline \multirow{4}{*}{$\begin{array}{l}\text { A. Quality of Team } \\
\text { Management }\end{array}$} & A1. Establish a well-furnished system for pay and benefits & 0.042 \\
\hline & A2. Establish a well-furnished administrative method and reward system for players and coaches & 0.038 \\
\hline & A3. Establish a sound insurance system for players and coaches & 0.036 \\
\hline & A4. Establish a coach training system & 0.036 \\
\hline \multirow{4}{*}{$\begin{array}{l}\text { B. Development of } \\
\text { Volleyball at Basic } \\
\text { Level }\end{array}$} & B1. Strengthen youth, college, and amateur skill levels & 0.040 \\
\hline & B2. Strengthen coaching expertise and tactical ability & 0.037 \\
\hline & B3. Establish a sponsorship platform for basic level teams & 0.043 \\
\hline & B4. Create events for professional teams to teach in the countryside & 0.034 \\
\hline \multirow{5}{*}{$\begin{array}{l}\text { C. Stimulation of } \\
\text { Sports Industry }\end{array}$} & C1. Seize opportunities to host prestigious international events & 0.034 \\
\hline & C2. Increase interaction between international and professional volleyball leagues & 0.034 \\
\hline & C3. Establish a ticketing system and develop patterns for audience ticket purchase & 0.034 \\
\hline & C4. Establish a platform for team sponsorship & 0.034 \\
\hline & C5. Increase the sales of mascots and souvenirs in exclusive competitions & 0.033 \\
\hline \multirow{9}{*}{$\begin{array}{l}\text { D. Application of } \\
\text { Marketing Strategy }\end{array}$} & D1. Establish territorialism and regulate local fans & 0.020 \\
\hline & D2. Each team develops a system to develop unique characteristics of fans & 0.020 \\
\hline & D3. Create brand recognition for each team & 0.019 \\
\hline & D4. Emphasize the upkeep of star players' public image and conduct & 0.020 \\
\hline & D5. Establish a link between official website and social media, to strengthen marketing & 0.019 \\
\hline & D6. Establish complete statistics of offense and defense, and post them on official websites & 0.017 \\
\hline & D7. Integrate cross-industry marketing to develop fans & 0.018 \\
\hline & D8. Develop a service platform to assist fans & 0.019 \\
\hline & D9. Strategize marketing and media planning & 0.020 \\
\hline \multirow{3}{*}{$\begin{array}{l}\text { E. Stupendousness } \\
\text { of the Game }\end{array}$} & E1. Improve the standard of competitions and athletes & 0.067 \\
\hline & E2. Facilitate improvement of professional media coverage and quality & 0.053 \\
\hline & E3. Increase the maturity of the league and attract foreign skilled athletes & 0.060 \\
\hline \multirow{5}{*}{$\begin{array}{l}\text { F. Competitive } \\
\text { System of } \\
\text { Professional } \\
\text { Volleyball }\end{array}$} & F1. Establish a complete draft system & 0.037 \\
\hline & F2. Establish complete association regulations and competition rules & 0.037 \\
\hline & F3. Establish a system of wage arbitration & 0.032 \\
\hline & F4. Establish a trade system between teams & 0.032 \\
\hline & F5. Establish a system for all-star games & 0.035 \\
\hline
\end{tabular}

development dimensions, techniques, important trends, and correlations within a database were discovered and conveyed visually, and priorities for development were identified. The results show that Stupendousness of the Game, Quality of Team Management, and Application of Marketing Strategy are the major driving forces of the professionalization of volleyball. Advancing the standard of competitions and athletes' skills will raise the competitiveness of volleyball in the sports industry. Mature leagues usually attract skilled foreign athletes. The presences of foreign players raises the stupendousness of the game and balances the skill level among the league's teams, thus increasing the excitement of the offense and defense. The future work needs to compare the results with those come from various multiple criteria decision-making methods based on a rigorous examination scheme. ${ }^{27}$

\section{Acknowledgement}

This study was supported by the Sports Development Fund, Sports Administration, Ministry of Education, Taiwan (2015), and the Ministry of Science and Technology, Taiwan (MOST 104-2410-H-031-033MY3).

\section{References}

1. A. W. Jones, At the gate and beyond Outlook for the sports market in North America. PwC Sports Outlook. (2015) 3 3.

2. C. P. Shih and H. H. Huang, A Study of Constructing Spectators' Satisfaction Model on Chinese Professional Baseball League Marketing Strategies. Physical Education Journal, 42(3) (2009) 77-93. 
3. M. L. Chang and L. Y. Yao, The Relationship between Brand Personality and Team Identification: CPBL Team as an Example, Journal of Sport and Recreation Management, 7(1) (2010) 55-69.

4. S. S. Lee, H. T. Hsu, C. F. Chen and C. H. Hu, How to Measure Team Image of Professional Baseball Team: The Case of Sinon Bulls Fans of Chinese Professional Baseball League. Journal of Sport and Recreation Mana gement, 19(1) (2012) 100-113.

5. J. S. Horng, S. F. Chou, C. S. Liu and C. Y. Tsai, Creativity, aesthetics and ecofriendliness: a physical dining environment design synthetic assessment model of innovative restaurants. Tourism Management, 36(2013) $15-25$.

6. D. K. Kardaras, B. Karakostas and X. J. Mamakou, Content presentation personalization and media adaptation in tourism web sites using Fuzzy Delphi method and fuzzy cognitive maps. Expert Systems with Applications, 40(6) (2013) 2331-2342.

7. F. Tahriri, M. Mousavi, S. Hozhabri Haghighi and S. Zawiah Md Dawal, The application of fuzzy Delphi and fuzzy inference system in supplier ranking and selection. Journal of Indu strial Engineering International, 10(3) (2014)1-16.

8. C. H. S. Liu and S. F. Chou, Tourism strategy development and facilitation of integrative processes among brand equity, marketing and motivation. Tourism Management, 54 (2016) 298-308.

9. L. C. Leung, K. C. Lam and D. Cao, Implementing the balanced scorecard using the analytic hierarchy process \& the analytic network process, The Journal of th $e$ Operational Research Society. 57(6) (2006) 682-691.

10. V. Ravi and R. Shankar, Analysis of interactions among the barriers of reverse logistics, Technological Forecasting and Social Change. 72 (2005) 1011-1029.

11. Y. P. Ou Yang, H. M. Shieh and G. H. Tzeng, A VIKOR technique based on DEMATEL and ANP for information security risk control assessment, Information Sciences 232 (2013) 482-500

12. A. Baykasoglu and Z. D. U. Durmusoglu, A Hybrid MCDM for private primary school assessment using DEMATEL Based on ANP and Fuzzy Cognitive Map, International Journal of Computational Intelligence Systems, 7(4) (2014) 615-635.

13. C. W. Chung and J. Y. Huang, Application of Fuzzy Delphi Method to the Study of Urban Marketing of Festival Activities. Museology Quarterly, 28(4) (2014) 79-92.

14. A. L. Delbecq, A. H. Van de Ven and D. H. Gustafson, Group Techniques for Program Planning: A Guide to Nominal Group and Delphi Processes (Glenview, IL: Scott, Foresman, 1975).

15. Y. C. Shen, G. T. R. Lin and G.-H. Tzeng, Combined DEMATEL techniques with novel MCDM for the organic light emitting diode technology selection. Expert Systems with Applications, 38(3) (2011) 1468-1481.
16. W. M. Wey and K. Y. Wu, Interdependent urban renewal project selection under the consideration of resource constraints. Environment and Planning B - Planning and Design. 35(1) (2008) 122-147.

17. W. L. Wei and W. C. Chang, Analytic network processbased model for selecting an optimal product design solution with zero-one goal programming, Journal of Engineering Design, 19(1) (2008) 15-44.

18. T. L. Saaty, Decision Making with Dep endence and Feedback: The Analytic Netw ork Process, 2 nd edn. (Pittsburgh, PA: RWS Publications, 2001).

19. P. T. W. Lee, J.-Z. Wu, K.-C. Hu and M. Flynn, Applying Analytic Network Process (ANP) to Rank Critical Success Factors of Waterfront Redevelopment, International Journal of Shipping and Transport Logistics, 5(4/5) (2013) 390-411.

20. P. T. W. Lee, J.-Z. Wu, K. Suthiwartnarueput, K.-C. Hu and R. Rodjanapradied, A Comparative Study of Key Critical Factors of Waterfront Port Development: Case Studies of Incheon Inner Port and Bangkok Port, Growth and Change, 47(3) (2015) 393-405.

21. W.-H. Tsai and W.-C. Chou, Selecting management systems for sustainable development in SMEs: A novel hybrid model based on DEMATEL, ANP, and ZOGP, Expert Systems with Applications, 36(2) (2009) 1444-1458.

22. F.-H. Chen, T.-S. Hsu and G.-H. Tzeng, A balanced scorecard approach to establish a performance evaluation and relationship model for hot spring hotels based on a hybrid MCDM model combining DEMATEL and ANP, International Journal of Hospitality Management. 30(4) (2011) 908-932.

23. W.-Y. Chiu, G.-H. Tzeng and H.-L. Li, A new hybrid MCDM model combining DANP with VIKOR to improve E-store business, Knowledge-Based Systems. 37(1) (2013) 48-61.

24. J.-Z. Wu, C. H. Santoso and J. Roan, Key factors for truly sustainable supply chain management: An investigation of the coal industry in Indonesia, The International Journal of Logistics Management, 28(4) (2017) 1196-1217.

25. W. C. Lu and C. H. Yang, The Future Operation Strategies of the Enterprise Volleyball League with the Participation of Women's Teams, The University Physical Education \& Sports. 114(2011) 48-53.

26. P. J. Wu and H. P. He, A Study of the 2010 Business Volleyball League on the Correlation among Service Quality, Audience Satisfaction, and Audience Loyalty, Journal of Sport and Recreation Management, 9(2) (2012) 322-337.

27. J.-Z. $\mathrm{Wu}$ and P.-J. Tiao, A validation scheme for intelligent and effective multiple criteria decision-making, Applied Soft Computing, 68 (2018) 866-872. 